\title{
National Differences in Subjective Well-Being: The Interactive Effects of Extraversion and Neuroticism
}

\author{
Michael Lynn and Piers Steel
}

\begin{abstract}
Extraversion and neuroticism interact to affect subjective wellbeing (SWB) at the individual level of analysis, so that introverted neurotics tend to be particularly miserable. The goal of this study is to determine if this interaction can also be detected at a national level. Findings based on data from 30 countries confirmed that the interaction between extraversion and neuroticism was an extremely strong predictor of satisfaction with life and affect, and a similar though not significant effect was observed with happiness. Neuroticism lowered satisfaction with life and affect among all nations, but more so among introverted nations than among extraverted ones. These findings further confirm that personality traits can be used to extend our understanding of national differences regarding SWB. They also further validate national SWB scores, as they relate to personality in a complex but theoretically meaningful manner.
\end{abstract}

\section{Introduction}

Almost by definition, people everywhere strive for happiness and life satisfaction.

Unfortunately, research has found that the populations of some nations are less successful than others in achieving these desired states. For example, the percentage of those claiming to be happy ranges from a low of 44 in Moldova to a high of 97 in Iceland, while the percentage of those claiming to be satisfied with their lives ranges from a low of 20 in Ukraine to a high of 92 in the Netherlands (Inglehart and Klingemann, 2000). Although the validity of these subjective measures as well as their comparability across nations has been questioned, the available evidence suggests that the measures are reasonably valid and comparable (see Diener et al., 1995b; Veenhoven, 2000a). Thus, variations in national subjective wellbeing (SWB) appear to be both sizable and meaningful.

Recently, psychologists have begun to study the correlates/ determinants of these national differences. Some researchers have examined the impact on national SWB of economic and political forces, on the grounds that these factors can facilitate or impede goal attainment, which underlies 
satisfaction and happiness. Consistent with this reasoning, the research indicates that national SWB increases with national income/wealth and with economic and political freedom (Diener et al., 1995a; Inglehart and Klingemann, 2000; Veenhoven, 2000a). Other researchers have examined the impact on national SWB of cultural values, on the grounds that cultural values influence: (1) the environments that national populations create for themselves, (2) the perceptions and evaluations that national populations have of life situations, and/or (3) the goals that national populations strive for (with some goals being more conducive to happiness and satisfaction than others). This research indicates that national SWB increases with national disapproval of power differences between people, national tolerance of uncertainty, and national emphasis on trusting others (Diener and Suh, 1999). Still other researchers have examined the impact on national SWB of national character (or personality), on the grounds that personality influences the happiness and satisfaction of individuals. Although the results of these later studies are not entirely consistent, they generally indicate that national SWB increases with national extraversion and decreases with national neuroticism and psychoticism (Arrindell et al., 1997; Steel and Ones, 2002; van Hemert et al., 2002).

This study extends the use of national personality to predict national SWB. Specifically, it examines for the first time the impact on national SWB of the interaction between national extraversion (E) and national neuroticism (N). Empirical research at the individual level of analysis has already found that these personality traits interact to affect SWB. Following Eysenck (e.g., Eysenck and Eysenck, 1985), Hotard et al. (1989) argued that extraverts (who seek to increase arousal) interpret social arousal positively and seek out social interactions, while introverts (who seek to decrease arousal) interpret social arousal negatively and try to avoid social interactions. Neuroticism (or negative emotionality) amplifies the negative reactions of introverts to social stimuli, so that neurotic introverts are more socially withdrawn and less happy than the other three groups defined by the intersection of these personality traits. Consistent with the expectation regarding happiness, Hotard et al. (1989) found significant extraversion by neuroticism ( $\mathrm{E} \times \mathrm{N}$ ) interactions in three data sets with different measures of extraversion, neuroticism and SWB such that neurotic introverts were particularly unhappy and dissatisfied with their lives (see also Pavot et al., 1990). However, contrary to expectations, they did not find that neurotic introverts had fewer social relationships than neurotic extraverts. This later finding challenges the role of sociability in producing the $E \times N$ interaction on SWB. An alternative explanation is that the negative emotionality of neurotics is less distressing to extraverts, whose low levels of cortical arousal and consequent need for external stimulation cause them to dwell on negative emotions less 
than do introverts. Thus, this E X N interaction makes sense given Eysenck's conceptualization of extraversion as chronically low arousal (hence, insensitivity to external stimuli).

Relationships observed at the individual level may not occur at the group level (e.g., Ostroff, 1993). However, it is also possible that relationships may be even stronger at higher levels of analysis; this may occur with the $\mathrm{E} X \mathrm{~N}$ interaction. First, homology may occur, where the same processes exist at both levels of analysis. In this case, nations whose populations score low on extraversion and high on neuroticism may have a disproportionately large number of neurotic introverts whose dissatisfaction with their lives lowers the average SWB in those nations. Second, additional processes can magnify individual level effects. Specifically, past research has shown evidence of emotional contagion. As summarized by Hatfield et al. (1993), "People tend from moment to moment to 'catch' other people's emotions as a result of mimicry, feedback, and resulting synchrony in social encounters" (p. 96). Consequently, neurotic introverts will not only tend to be unhappy but may also make those they come in contact with less happy. Thus, it is possible that extraversion will interact with neuroticism to affect SWB at the national level of analysis as well as at the individual level of analysis. This possibility is examined for the first time in the following study.

\section{Method}

We re-analyze data compiled by Steel and Ones (2002) for their examination of national personality effects on national SWB (see Table I). Steel and Ones provide detailed information regarding the measurement equivalence of their personality and SWB data, that is, the degree to which the recorded differences among nations are meaningful and reflect true scores. Given a series of studies examining convergent and discriminant validity along with bilingual administration and differential item responding, they conclude that observed scores largely reflect true scores. Also, consistent with classical test theory, any measurement in-equivalence will simply add error, which will typically attenuate observed correlations. Consequently, if we could measure traits and SWB perfectly, any results we obtain would likely be significantly stronger. Steel and Ones also detail how their databases were compiled, which we review only briefly here.

\section{National Subjective Well-Being}

Steel and Ones (2002) obtained national scores on SWB from an international database of happiness surveys compiled by Veenhoven (2000b). These surveys were administered to different samples (e.g., students, general population), asked different questions (e.g., "how satisfied are you"), 
and had different numbers of response options (e.g., 1-5, 1-7). To put the scales on a common metric, Veenhoven used expert opinion, which Steel and Ones supplemented with linear equating when 20 cases or more were available (see Angoff, 1971). To determine if different SWB measures were functionally equivalent and could be aggregated (i.e., a sample-size weighted average), Steel and Ones examined differences among administration, sample, and question type. Correlational analysis indicated that students were not equivalent to the general population, and so exclusively student surveys were excluded from the aggregation. Also, questions regarding affect, happiness, and life satisfaction were significantly different, and these measures were aggregated separately. The final data set proved to be very similar to a previous compilation by Diener et al. (1995a), correlating together at 0.86 , though not identical due to small differences in data and methodology.

TABLE I

Sample of nations with their subjective well-being and personality scores

\begin{tabular}{|c|c|c|c|c|c|}
\hline Country & Satisfaction w/Life & Happiness & Affect & Extraversion & Neuroticism \\
\hline Australia & 7.15 & 7.57 & 6.87 & 19.31 & 15.48 \\
\hline Bangladesh & & 6.95 & & 19.05 & 12.29 \\
\hline Brazil & 6.51 & 7.01 & 6.17 & 17.63 & 14.20 \\
\hline Bulgaria & 5.22 & 5.36 & & 18.60 & 14.96 \\
\hline Canada & 7.17 & 7.25 & 7.29 & 18.05 & 12.77 \\
\hline China & 6.74 & 6.74 & 6.27 & 13.75 & 14.50 \\
\hline Czechoslovakia & 6.09 & 6.20 & 5.67 & 19.52 & 14.09 \\
\hline Egypt & 6.34 & & & 18.57 & 17.36 \\
\hline Finland & 7.02 & 7.13 & 6.18 & 16.26 & 14.60 \\
\hline France & 5.98 & 6.46 & 6.17 & 17.75 & 15.09 \\
\hline Germany FR & 6.71 & 6.75 & 6.38 & 18.40 & 13.68 \\
\hline Great Britain & 6.83 & 7.14 & 6.55 & 18.03 & 14.97 \\
\hline Greece & 5.47 & 5.77 & & 20.40 & 18.32 \\
\hline Hungary & 5.77 & 6.31 & 6.00 & 16.57 & 14.58 \\
\hline Iceland & 7.24 & 7.69 & 7.51 & 19.18 & 13.90 \\
\hline Israel & 6.55 & 6.33 & & 22.62 & 8.51 \\
\hline Italy & 5.88 & 6.09 & 6.06 & 18.37 & 16.66 \\
\hline Japan & 5.96 & 6.68 & 5.33 & 16.50 & 16.78 \\
\hline Lithuania & 5.90 & 5.89 & 5.60 & 16.45 & 15.10 \\
\hline Mexico & 6.67 & 6.76 & 6.48 & 20.63 & 14.15 \\
\hline Netherlands & 7.39 & 7.43 & 6.84 & 17.36 & 11.52 \\
\hline Nigeria & 6.13 & 6.78 & 6.54 & 24.50 & 9.43 \\
\hline Norway & 7.26 & 7.22 & 7.29 & 18.65 & 10.33 \\
\hline Portugal & 5.61 & 6.18 & 6.36 & 18.94 & 15.27 \\
\hline Puerto Rico & & 6.10 & & 21.01 & 14.15 \\
\hline Romania & 5.63 & 5.82 & 5.71 & 18.45 & 13.31 \\
\hline Russia & 5.34 & & 5.33 & 16.11 & 18.04 \\
\hline Singapore & 6.80 & 6.41 & & 17.42 & 13.02 \\
\hline South Korea & 5.84 & 6.81 & & 16.49 & 17.42 \\
\hline Spain & 6.29 & & 5.76 & 17.11 & 16.24 \\
\hline Sri Lanka & & 7.34 & & 18.67 & 12.09 \\
\hline Uganda & & 7.32 & & 19.43 & 15.78 \\
\hline United States & 6.99 & 7.75 & 6.89 & 21.53 & 15.20 \\
\hline Yugoslavia & 6.02 & & & 17.32 & 14.37 \\
\hline
\end{tabular}

Note: India omitted as an outlier as per Steel and Ones (2002) and McCrae (2001). 


\section{National Personality}

Steel and Ones (2002) compiled the results of 39 studies reporting mean EPQ scores on extraversion, neuroticism, and psychoticism among normal adult populations in various nations. This EPQ data was mostly the result of a rigorous data collection program led by Hans and Sybil Eysenck, using carefully translated scales administered to stratified samples. Since the scales of each study were of various lengths, Steel and Ones converted the results to standard 30-item metric. They also weighted male and female means within nations equally in order to avoid confounding national scores with gender differences. In addition, several serious typographic errors from previous publications were corrected, and one outlier, India, was addressed.

\section{Results}

The means and standard deviations of each variable along with their zero-order correlations with one another are presented in Table II. Prior to analysis, the national personality scores were standardized and centered (see Aiken and West, 1991). To assess the effect of E X N, hierarchical linear regression is recommended (Stone-Romero and Anderson, 1994), allowing the two main effects to enter first followed by the interaction. In this case, each of the dependent variables - national affect, happiness, and satisfaction with life - was regressed on the standardized extraversion and neuroticism scores followed by their product in the second step. The resulting $\mathrm{E} \times \mathrm{N}$ interactions were further examined by performing regressions of the dependent variables on neuroticism separately for extraverted and introverted nations, which were defined by extraversion scores greater and less than 18.3 respectively.

\section{TABLE II}

Descriptive statistics for, and correlations among, dependent and independent variables

\begin{tabular}{lrlllcrr}
\hline Variable & Mean & SD & $n$ & $\mathrm{~N}$ & Satisfaction & Affect & Happy \\
\hline E & 18.40 & 2.04 & 38 & $-0.38^{*}$ & 0.06 & 0.39 & 0.01 \\
N & 14.34 & 2.14 & 38 & & $-0.47^{* *}$ & $-0.57^{* *}$ & -0.20 \\
Satisfaction & 6.38 & 0.61 & 33 & & & $0.81^{* *}$ & $0.85^{* *}$ \\
Affect & 6.33 & 0.59 & 25 & & & & $0.77^{* *}$ \\
Happy & 6.70 & 0.58 & 35 & & & & \\
\hline
\end{tabular}

* Correlation is significant at the 0.05 level.

** Correlation is significant at the 0.01 level. 
The $\mathrm{E} \times \mathrm{N}$ interaction had a positive and statistically significant effect on national satisfaction with life $\left(\Delta R^{2}=0.14, \beta=0.462, t(26)=2.41, p<0.05\right)$ and national affect $\left(\Delta R^{2}=0.19, \beta=0.500, t(19)=2.76\right.$, $p<0.05)$, and a positive but non-significant effect on national happiness $\left(\Delta R^{2}=0.04, \beta=0.259, t(26)=1.03\right.$, $p=0.31)^{i}$. This is consistent with previous research indicating weaker relationships with the happiness operationalization of SWB (Steel and Ones, 2002). For introverted nations, national neuroticism was strongly and negatively related to national satisfaction with life $\left(R^{2}=0.65, \beta=-0.81, t(13)=-4.95, p<0.001\right)$ and national affect $\left(R^{2}=0.76, \beta=-0.87, t(10)=-5.55, p<0.001\right)$. However, for extraverted nations, national neuroticism was only weakly related to these variables: national satisfaction with life $\left(R^{2}=0.10, \beta=-0.32\right.$, $t(13)=-1.22, p=0.25)$ and national affect $\left(R^{2}=.07, \beta=-0.26, t(9)=0.80, p=0.44\right)$. For another perspective on these interactions, see Table III.

\section{Discussion}

Uncovering a significant interaction effect is uncommon, as they are notoriously difficult to detect in the field (McClelland and Judd, 1993). This study found that the interaction between national extraversion and national neuroticism affected national satisfaction with life and national affect, but not national happiness, at a statistically significantly level. Neuroticism lowered satisfaction with life and affect among all nations, but more so among introverted nations than among extraverted ones. These findings contribute to our understanding of national differences, SWB, and personality as discussed below.

First, these findings support the idea that national differences in SWB are influenced to a large degree by differences in the personalities of the nations' populations. In fact, national extraversion, neuroticism and their interaction accounted for $38 \%$ of the variability in national satisfaction with life and $42 \%$ of the variation in national affect. The interaction alone, which was examined here for the first time, accounted for $14 \%$ and $19 \%$ of the variability in national satisfaction with life and national affect respectively. This is a huge effect, given that a moderate interaction effect is considered to be around 4\% (Evans, 1985). The data are only correlational, so caution must be used in inferring causation. However, the observed national level interactions are consistent with those at the individual level of analysis, and the simplest explanation for both sets of findings is homology, that extraversion and neuroticism interact to affect SWB. At the individual level, extraverts find the negative emotionality associated with neuroticism to be less distressing than do introverts. At the national level, disproportionately large numbers of neurotic introverts lower the average SWB of nations whose populations are high on neuroticism and low on extraversion. 
TABLE III

Means (and samples sizes) of dependent variables by high and low $\mathrm{E}$ and $\mathrm{N}^{\mathrm{a}}$

\begin{tabular}{llllll}
\hline Dependent variable & \multicolumn{2}{l}{ Introverted (low E) nations } & & \multicolumn{2}{l}{ Extraverted (high E) nations } \\
\cline { 2 - 3 } \cline { 6 - 7 } & Low N & High N & & Low N & High N \\
\hline Satisfaction & $6.76(n=7)$ & $6.12(n=8)$ & & $6.51(n=7)$ & $6.08(n=8)$ \\
Affect & $6.59(n=5)$ & $5.82(n=7)$ & & $6.53(n=6)$ & $6.47(n=5)$ \\
Happiness & $6.93(n=6)$ & $6.66(n=6)$ & & $6.72(n=10)$ & $6.56(n=8)$ \\
\hline
\end{tabular}

${ }^{a}$ Low $\mathrm{E}=\mathrm{E}<18.3$, High $\mathrm{E}=\mathrm{E}>18.3$, Low $\mathrm{N}=\mathrm{N}<14.55$, High $\mathrm{N}=\mathrm{N}>14.55$.

These findings also support the validity of both national EPQ scores and national SWB scores. Measures that are valid at the individual level of analysis may not remain valid when aggregated to the national level, for a variety of reasons reviewed by Steel and Ones (2002). Previous research has addressed some of these concerns as they relate to national EPQ scores and national SWB scores. For example, Barrett et al. (1998) demonstrated that the EPQ had a similar factor structure across 34 countries, and Diener et al. (1995b) found little evidence that response artifacts contributed to national differences in SWB. However, evidence supporting the validity of national extraversion, neuroticism and SWB scores is still sparse. The fact that those scores in this study were related to one another in a complex (i.e., an interaction) but theoretically meaningful way provides additional evidence that they are valid. In turn, this evidence of measurement validity should encourage additional research on national differences in personality and SWB. Traits appear to be critical determinants of an important national quality and should not be neglected.

Finally, recent studies examining international SWB have focused almost exclusively on the main effects of direct environmental factors, such as unemployment and political stability (e.g., Kekic, 2005), or of individual personality traits, such as extraversion and neuroticism (e.g., Steel and Ones, 2002). The current study took a step forward by examining the interaction of two national personality traits. The next step is to determine if homology occurs for other types of interactions, specifically between environmental variables and national personality traits. For example, the effects of aversive environmental conditions on national SWB may be stronger among highly neurotic nations than among less neurotic nations. Once the interactions of environmental variables and national personality on national SWB are understood, we will be in a better position to set public policy aimed at increasing global SWB. 


\section{References}

Aiken, L.S. and S.G. West: 1991, Multiple Regression: Testing and Interpreting Interactions (Sage, Newbury Park, CA).

Angoff, W.H.: 1971, Norms, scales, and equivalent scores, in R.L. Thorndike (ed.), Educational Measurement 2nd edition, (American Council on Education, Washington, DC), pp. 508-600.

Arrindell, W.A., C. Hatzichristou, J. Wensink, E. Rosenberg, B. van Twillert, J. Stedema and D. Meijer: 1997, 'Dimensions of national culture as predictors of cross-national differences in subjective well-being', Personality and Individual Differences 23, pp. 37-53.

Barrett, P.T., K.V. Petrides, S.B.G. Eysenck and H.J. Eysenck: 1998, 'The Eysenck Personality Questionnaire: An examination of the factorial similarity of $P, E, N$, and L across 34 countries', Personality and Individual Differences 25, pp. 805-819.

Diener, E. and E.M. Suh: 1999, National differences in subjective well-being, in E. Kahneman, E. Diener and N. Schwarz (eds.), Well-being: The Foundations of Hedonic Psychology (Russell Sage Foundation, New York), pp. 434-450.

Diener, E., M. Diener and C. Diener: 1995a, 'Factors predicting the subjective well-being of nations', Journal of Personality and Social Psychology 69, pp. 851-864.

Diener, E., E.M. Suh, H. Smith and L. Shao: 1995b, 'National differences in reported subjective wellbeing: Why do they occur?', Social Indicators Research 34, pp. 7-32.

Evans, M.G.: 1985, 'A Monte Carlo study of the effects of correlated method variance in moderated multiple regression analysis', Organizational Behavior and Human Decision Processes 36, pp. 305-323.

Eysenck, H. J. and M. W. Eysenck: 1985, Personality and Individual Differences: A Natural Science Approach (Plenum, New York).

Hatfield, E., J.T. Cacioppo and R.L. Rapson: 1993, 'Emotional contagion', Current Directions in Psychological Science 2, pp. 96-99.

Hemert, D.A.van, F.J.R. Vijvervan de, Poortinga Y.H. and J. Georgas: 2002, 'Structural and functional equivalence of the Eysenck Personality Questionnaire within and between countries', Personality and Individual Differences 33, pp. 1229-1249.

Hotard, S.R., R.M. McFatter, R.M. McWhirter and M.E. Stegall: 1989, 'Interactive effects of extraversion, neuroticism, and social relationships on subjective well-being', Journal of Personality and Social Psychology 57, pp. 321-331. 
Inglehart, R. and H.D. Klingemann: 2000, Genes, culture, democracy, and happiness, in E. Diener and E.M. Suh (eds.), Culture and Subjective Wellbeing (Bradford, Cambridge, MA), pp. 163-184.

Kekic, L.: 2005, The world's best country [Electronic Version]. The Economist. Retrieved June 10, 2005, from http://www.economist.com/theworldin/international/displayStory.cfm? story_id=3372495\&d=2005.

McClelland, G. and C. Judd: 1993, 'Statistical difficulties of detecting interactions and moderator effects', Psychological Bulletin 114, pp. 376-390.

Ostroff, C.: 1993, 'Comparing correlations based on individual-level and aggregated data', Journal of Applied Psychology 78, pp. 569-582.

Pavot, W., E. Diener and F. Fujita: 1990, 'Extraversion and happiness', Personality and Individual Differences 11, pp. 1299-1306.

Steel, P. and D.S. Ones: 2002, 'Personality and happiness: A national-level analysis', Journal of Personality and Social Psychology 83, pp. 767-781.

Stone-Romero, E.F. and L.E. Anderson: 1994, 'Relative power of moderated multiple regression and the comparison of subgroup correlation coefficients for detecting moderated effects', Journal of Applied Psychology 79, pp. 354- 359.

Tabachnick, B.G. and F.S. Fidell: 1989, Using Multivariate Statistics 2nd (HarperCollins Publisher Inc, New York).

Veenhoven, R.: 2000a, Freedom and happiness: A comparative study in forty-four nations in the early 1990's, in E. Diener and E.M. Suh (eds.), Culture and Subjective Well-being (Bradford, Cambridge, MA), pp. 257-288.

Veenhoven, R.: 2000b, Happiness in nations. World Database of Happiness. Retrieved from http://www.eur.nl/fsw/research/happiness/

\footnotetext{
'In addition, as with any smaller dataset, outliers can exert undue influence on the results. Though the dataset did not have any univariate outliers, we also searched for any chi-square significant multivariate outliers using Mahalanobis distance (critical v2 at a=0.001 for $3 \mathrm{df}$ is 16.27) as per Tabachnick and Fidell (1989). For satisfaction and happiness, there were no significant outliers. For affect, Nigeria did prove extreme. Again, as per Tabachnick and Fidell, we altered the "outlying case(s) so that they are deviant, but not so deviant as they were" ( $p$. 70). This reduced the effect size of affect, though it still remained practically and statistically significant. $\left(R^{2}=0.11, \beta=0.332\right.$, $F=4.40, p<0.05)$.
} 